Aspirasi: Jurnal Masalah-Masalah Sosial | Volume 11, No. 1 Juni 2020

ISSN: 2086-6305 (print) ISSN: 2614-5863 (electronic)

doi: 10.22212/aspirasi.v11i1.1589

link online: http://jurnal.dpr.go.id/index.php/aspirasi/index

\title{
Urgensi Revisi Undang-Undang tentang Kesejahteraan Lanjut Usia
}

\author{
The Urgency of The Elderly Welfare Law Revision
}

\section{Lukman Nul Hakim}

lukman.nulhakim@dpr.go.id

Pusat Penelitian Badan Keahlian DPR RI

Jl. Gatot Subroto, Senayan, Jakarta

Naskah diterima: 30 Maret 2020 | Naskah direvisi: 5 Juni 2020 | Naskah diterbitkan: 30 Juni 2020

\begin{abstract}
At present we are witnessing an increasing population of the world's elderly. The World Health Organization (WHO) calls this phenomenon as humanity's greatest triumph. Indonesia is one of the countries with the most elderly population in the world. The WHO predicts that in 2025 Indonesia will occupy the fifth position with the highest percentage of elderly people in the world. This article tries to answer what is the latest scientific study of the elderly? What should be the category limit old age in Indonesia? Is the revision of the Law Number 13 of 1998 concerning Elderly Welfare (the Elderly Act) is urgent to do? Finally, what is the role of the Indonesian Parliament on this issue? The researcher uses a qualitative method with a combination of interview techniques and literature studies. This article tries to answer what is the latest scientific study of the elderly? What should be the category limit old age in Indonesia? Is the revision of the Law Number 13 of 1998 concerning Elderly Welfare (the Elderly Act) is urgent to do? Finally, what is the role of the Indonesian Parliament on this issue? So if there is an elderly bonus, the burden on productive people will be heavier. Gerontologists introduce the concept of active aging as a solution. A concept that invites us to see the elderly not as burdens but people with economic and social potential. A solutive, comprehensive and implementative policy that is supported by implementers at the central, regional, and community level will make the bonus of the elderly a blessing. Therefore, the revision of Law No. 13 of 1998 on Elderly Welfare is urgently called for, with several important things that must be included, namely the principle of humanity, the rights of the elderly, elderly data collection, and economic protection for the elderly.
\end{abstract}

Keywords: active aging; elderly; elderly bonus; law; welfare

\begin{abstract}
Abstrak: Saat ini kita sedang menyaksikan meningkatnya populasi lanjut usia (lansia) di dunia. World Health Organization (WHO) menyebut fenomena ini sebagai kemenangan terbesar umat manusia. Indonesia merupakan salah satu negara yang mempunyai populasi lansia terbanyak di dunia. WHO memprediksi bahwa pada tahun 2025 Indonesia akan menempati posisi kelima negara dengan persentase lansia tertinggi di dunia. Artikel ini mencoba menjawab bagaimanakah kajian ilmiah terkini tentang lansia? Berapakah sebaiknya batasan kategori usia lansia di Indonesia? Apakah revisi Undang-Undang Nomor 13 Tahun 1998 tentang Kesejahteraan Lanjut Usia (UU Lansia) mendesak untuk dilakukan? Terakhir, bagaimana peran DPR RI mengenai isu ini? Peneliti menggunakan metode penelitian kualitatif, yaitu dengan kombinasi teknik wawancara dengan pakar dan kajian literatur. Berdasarkan perhitungan dependency ratio oleh BPS, pada tahun 2020 ini 100 orang usia produktif menanggung beban 48 orang nonproduktif sehingga jika terjadi bonus lansia maka beban orang produktif akan semakin berat. Para ahli gerontologi memperkenalkan konsep active ageing sebagai solusi. Sebuah konsep yang mengajak kita memandang lansia bukan sebagai beban melainkan orang-orang yang potensial secara ekonomi dan sosial. Sebuah kebijakan yang solutif, komprehensif, dan implementatif yang didukung oleh para pelaksana di tingkat pusat, daerah, dan unsur masyarakat akan menjadikan bonus lansia sebagai berkah. Karena
\end{abstract}


itu, revisi UU Lansia mendesak dilakukan, dengan beberapa hal penting yang harus dimasukkan, yaitu prinsip kelanjutusiaan, hak-hak lansia, pendataan lansia, dan proteksi ekonomi bagi lansia.

Kata Kunci: active ageing; bonus lansia; kesejahteraan; lanjut usia; undang-undang

\section{Pendahuluan}

Semakin banyaknya populasi lanjut usia (lansia) di seluruh dunia merupakan cerminan kesuksesan ilmu pengetahuan, utamanya bidang kesehatan. Populasi lansia dunia diperkirakan akan meningkat $223 \%$ atau sebesar 694 juta orang antara tahun 1970-2025. Angka tersebut bahkan diperkirakan akan mencapai 2 miliar orang pada tahun 2050, dan $80 \%$ dari populasi tersebut berada di negara-negara berkembang (WHO, 2002). Kondisi ini membuat komposisi penduduk dunia yang sebelumnya berbentuk piramida pada tahun 2002 akan berubah mendekati bentuk silinder pada tahun 2025 (Grafik 1).

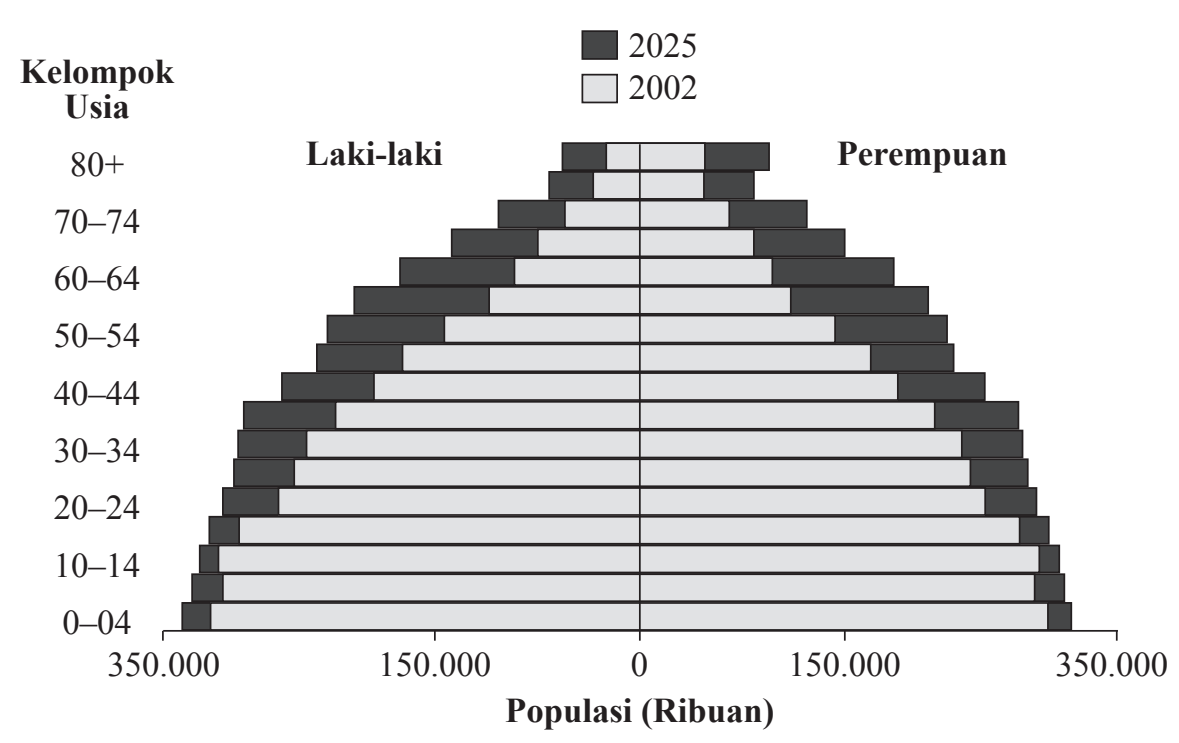

Grafik 1. Piramida Populasi Global, Tahun 2002 dan 2025

Sumber: WHO, 2002

WHO (2002) memprediksi Indonesia akan menjadi salah satu negara dengan peningkatan lansia yang terbesar di dunia. Tabel 1 memberikan gambaran perbandingan populasi lansia Indonesia di antara 11 negara dengan persentase lansia tertinggi di dunia, dengan membandingkan data tahun 2002 dan estimasi tahun 2025. Tabel tersebut menunjukkan bahwa populasi lansia di Indonesia berpotensi naik satu tingkat menjadi nomor 5 di dunia pada tahun 2025.

Menurut data BPS (2019) di Indonesia dalam waktu hampir lima dekade (1971-2019) telah terjadi peningkatan sekitar dua kali lipat sehingga persentase lansia menjadi 9,6\% atau sekitar 25,64 juta orang. Sementara ambang batas sebuah negara disebut sebagai negara dengan
Tabel 1.

Jumlah Orang Berusia di Atas 60 Tahun di Beberapa Negara dengan Total Populasi Mendekati atau di Atas 100 Juta Penduduk (dalam Jutaan), Tahun 2002 dan 2025

\begin{tabular}{|c|c|c|c|}
\hline No & Negara & 2002 & 2025 \\
\hline 1. & Tiongkok & 134,2 & 287,5 \\
\hline 2. & India & 81,0 & 168,5 \\
\hline 3. & Amerika Serikat & 46,9 & 86,1 \\
\hline 4. & Jepang & 31,0 & 43,5 \\
\hline 5. & Federasi Rusia & 26,2 & 35,0 \\
\hline 6. & Indonesia & 17,1 & 33,4 \\
\hline 7. & Brazil & 14,1 & 32,7 \\
\hline 8. & Pakistan & 8,6 & 18,3 \\
\hline 9. & Mexico & 7,3 & 17,7 \\
\hline 10. & Bangladesh & 7,2 & 17,6 \\
\hline 11. & Nigeria & 5,7 & 11,4 \\
\hline
\end{tabular}

Sumber: PBB dalam WHO, 2002 
struktur penduduk tua (ageing population) adalah jika telah lebih dari $10 \%$. Kondisi ini menunjukkan peningkatan usia harapan hidup (UHH) rakyat Indonesia. Jika pada tahun 2010 adalah 69,81 tahun, maka 9 tahun kemudian yaitu pada tahun 2019 menjadi 71,34. Pada grafik berikut tergambar tren kenaikan UHH penduduk Indonesia setiap tahunnya.

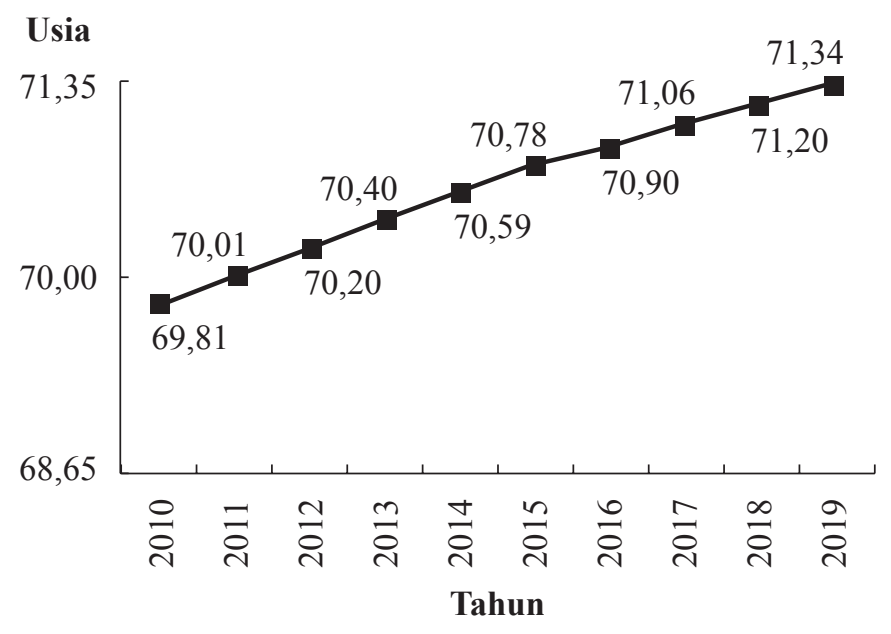

\section{Grafik 2. Usia Harapan Hidup Penduduk Indonesia Saat Lahir, Tahun 2010-2019 Sumber: Badan Pusat Statistik, 2019}

Dari Grafik 2 di atas terlihat telah terjadi peningkatan UHH sekitar 1,53 tahun dalam rentang hanya sembilan tahun. Menurut Bloom, Canning, dan Malaney (1999) besarnya populasi lansia tersebut merupakan masa bonus demografi kedua. Bonus demografi adalah sebuah kondisi ketika jumlah penduduk usia produktif lebih besar dari jumlah penduduk usia nonproduktif. Perbedaan antara masa bonus demografi pertama dan kedua adalah pada masa bonus demografi pertama peran utama pembangunan dilakukan oleh penduduk usia produktif. Sementara pada masa bonus demografi kedua, peran itu dilakukan oleh penduduk usia nonproduktif, yaitu lansia (Rapih, 2019).

Bonus demografi kedua atau bonus lansia ini mempunyai dua sisi, di satu sisi dapat berdampak positif dan di sisi lain bisa juga berdampak negatif. Lansia yang sehat dan mandiri akan dapat mengaktualisasikan dirinya bagi lingkungan sekitarnya. Pengalamannya akan menjadi aset untuk terciptanya lingkungan yang berkualitas. Namun, di sisi lain peningkatan jumlah lansia akan ikut meningkatkan tuntutan ekonomi dan sosial di berbagai negara (WHO, 2002). Terutama jika lansia tersebut tidak mampu lagi aktif dalam kegiatan ekonomi maupun sosial.

Berbagai kondisi ini harus disikapi dengan serius oleh pengelola negara baik itu eksekutif, legislatif, maupun yudikatif. Pemerintah melalui Kementerian Sosial telah menyuarakan pentingnya untuk memulai langkah-langkah antisipatif ini melalui revisi Undang-Undang Nomor 13 Tahun 1998 tentang Kesejahteraan Lanjut Usia (UU Lansia). Kementerian Sosial telah mewacanakan hal ini sejak saat Menteri Sosial dijabat Agus Gumiwang Kartasasmita, yaitu pada tahun 2019. Menurut Agus terdapat beberapa alasan yang mendasari usulan perubahan tersebut, di antaranya karena saat ini UHH masyarakat Indonesia terus meningkat dari rata-rata 70,1 pada tahun 2014 kemudian meningkat menjadi 71 tahun pada tahun 2018 (Purnamawati, 2019). Peningkatan UHH itu diiringi banyaknya masyarakat berusia di atas 60 tahun yang masih tetap produktif, aktif, dan mempunyai banyak gagasan. Kementerian Sosial selanjutnya memberikan ide untuk meningkatkan batasan usia lansia dari 60 tahun menjadi 65 tahun.

Wacana revisi UU Lansia juga didukung oleh Direktur Jenderal Rehabilitasi Sosial, Edi Suharto. Menurut Edi, UU Lansia yang ada saat ini telah berusia 22 tahun sehingga perlu dilakukan revisi agar sesuai dengan situasi dan kondisi saat ini (Astuti, 2018). Edi Suharto juga menyatakan bahwa terdapat tiga isu besar terkait lansia yang ingin menjadi fokus negara, yaitu kemiskinan, keterlantaran, dan perlindungan. Fenomena bonus lansia ini membutuhkan penanganan bersama dari semua unsur pengelola negara.

Berdasarkan berbagai kondisi terkait lansia di atas, DPR RI kemudian menetapkan Rancangan Undang-Undang tentang Perubahan atas Undang-Undang Nomor 13 Tahun 1998 tentang Kesejahteraan Lanjut Usia sebagai salah satu dari 248 undang-undang (UU) yang masuk dalam program legislasi nasional (Prolegnas) untuk masa kerja 2020-2024. Artikel ini berusaha menjawab beberapa pertanyaan yaitu: pertama, bagaimanakah kajian ilmiah terkini yang dapat digunakan sebagai dasar kebijakan 
untuk lansia yang lebih berkualitas? Kedua, berapakah sebaiknya batasan kategori usia lansia di Indonesia? Ketiga, apakah revisi UU Lansia mendesak untuk dilakukan? Keempat, bagaimana DPR RI dapat mengambil peran dalam upaya menangani bonus lansia?

Untuk dapat menjawab pertanyaanpertanyaan tersebut peneliti melakukan kajian dengan menggunakan metode kualitatif. Pengumpulan data dilakukan dengan menggabungkan teknik wawancara terhadap para pakar dan melakukan kajian literatur. Wawancara dilakukankepada pakar demografi dariUniversitas Indonesia, pakar kajian lansia Fakultas Psikologi Universitas Udayana, dan Kementerian Sosial. Peneliti menanyakan tentang hal-hal yang mendesak UU Lansia direvisi, tentang kelebihan dan kekurangan UU yang lama, serta hal-hal baru yang penting untuk dimasukkan dalam revisi UU. Selain itu, ditanyakan juga tentang isu-isu dan hasil penelitian terkini dalam ilmu psikologi tentang lansia yang dapat mendukung kebijakan yang komprehensif tentang lansia. Peneliti juga melakukan kajian literatur terhadap jurnal, buku, dan berita media massa terkini. Dari data yang diperoleh kemudian dilakukan koding sambil dilakukan perbandingan antara masukan dari narasumber, antara narasumber dengan literatur (constant comparison), untuk kemudian ditarik kesimpulan penelitian.

\section{Lanjut Usia}

Usia adalah indeks yang menempatkan individu-individu dalam urutan perkembangan (Fry, 1976: 175). Lebih lanjut Fry (1976: 170) menjelaskan bahwa usia hanyalah indeks kasar dari proses menua yang bersifat biologis, psikologis, sosiologis, dan budaya. Lansia merupakan salah satu babak dari rentang kehidupan manusia yang alamiah. Setelah sekitar sembilan bulan berada dalam kandungan ibu, kemudian lahir, menjadi bayi, tumbuh menjadi anak-anak, kemudian memasuki masa remaja, lalu masa dewasa, dan masa lanjut usia.

Secara fisik kondisi tubuh lansia menjadi lebih lemah dibanding masa muda. Sering kali fungsi panca indera lansia mengalami kemunduran. Gerakan motorik kasar maupun halus juga sering kali terganggu. Kondisi ini mengakibatkan para lansia terbatas mobilitasnya. Secara sosial lansia tidak bisa bersosialisasi seperti di masa muda, dan pada kondisi tertentu lansia menjadi tergantung dengan orang lain. Kondisi fisiknya mengharuskan mereka selalu didampingi jika melakukan aktivitas di luar rumah.

Secara psikis lansia juga mengalami kemunduran. Tantangan yang sering muncul adalah rasa kesepian dan fungsi mengingat yang terhambat. Para lansia yang telah ditinggal meninggal oleh pasangannya sering kali merasa kesepian. Ditambah lagi dengan semakin sedikitnya teman-teman di masa muda, baik itu karena kematian, pindah rumah, ataupun karena mereka tidak bisa banyak beraktivitas. Kondisi-kondisi tersebut membuat para lansia semakin mudah merasa kesepian dan menjadi lemah secara psikis. Di sisi lain, berkurangnya teman-teman masa muda membuat lansia harus berteman dengan teman-teman baru yang secara usia lebih muda. Proses tersebut membutuhkan proses adaptasi yang tidak mudah dan melelahkan secara psikis.

Kondisi menjadi lebih buruk pada lansia yang terbatas secara ekonomi. Terutama lansia yang telah berkurang penghasilannya, baik karena pensiun atau sudah tidak mampu bekerja lagi karena kondisi fisik dan psikis yang tidak mendukung. Kondisi-kondisi di atas merupakan masalah-masalah yang sering kali harus dihadapi dan ditangani oleh lansia. Oleh karena itu, proses penuaan penduduk mempunyai tantangan luas terhadap kehidupan sosial, ekonomi, dan kultural, baik bagi individu, keluarga, masyarakat, maupun komunitas global (UNPF, 2012).

Ram, Gerstorf, Fauth, Zarit, dan Malmberg (2010) menyatakan bahwa penuaan terbagi atas tiga jenis, yaitu penuaan primer atau normal, penuaan sekunder atau patologis, dan penuaan tersier atau kematian. Penuaan primer adalah perubahan khas yang dialami kebanyakan orang seiring bertambahnya usia, yaitu proses penurunan fungsi tubuh yang bertambah seiring bertambahnya usia dan secara kausal terkait dengan kerusakan biologis dan fisik terkait usia. Sementara penuaan sekunder adalah perubahan yang diakibatkan penyakit dan kecacatan. Penuaan tersier adalah kemunduran fungsional yang dipercepat yang terjadi sebelum kematian. 
Perubahan tersier ini tidak begitu berkorelasi dengan usia, namun dengan kematian yang akan datang.

Proses degeneratif yang dialami lansia yang disebabkan penuaan primer merupakan sebuah kondisi alamiah yang tidak bisa dihindari. Akan tetapi, permasalahan degeneratif yang disebabkan oleh faktor penyakit merupakan kondisi yang dapat diantisipasi. Negara mempunyai peluang untuk melakukan intervensi agar jumlah lansia yang merupakan lansia dengan penuaan sekunder, dengan penyakit-penyakit degeneratif bisa berkurang. Penyakit yang diderita seseorang sering kali membuat kualitas kondisi fisiknya dan keberfungsiannya tidak sesuai dengan usianya. Hal ini mendasari adanya dua perspektif mengenai usia lansia, yaitu usia kronologis dan usia fungsional. Kelompok yang pertama mendefinisikan lanjut usia berdasarkan usia kronologis (chronological age), sementara kelompok kedua berdasarkan usia fungsional (functional age).

\section{Usia Fungsional vs Usia Kronologis}

Secara umum upaya mendeskripsikan usia seseorang yang paling umum adalah menggunakan pendekatan usia kronologis. Pendekatan kronologis lebih banyak digunakan dalam membuat kategorisasi usia karena lebih memudahkan, terutama dalam membuat kebijakan. Sementara kelompok kedua melihat lanjut usia dari keberfungsian orang tersebut dalam kehidupan sehari-hari. Seseorang dengan usia kronologis 60 tahun bisa saja memiliki keberfungsian seperti orang berusia 50 tahun, atau sebaliknya orang berusia 50 tahun akan tetapi kondisinya seperti orang berusia 60 tahun. Namun, penerapan pendekatan ini masih dalam tahap konseptual. Pendukung konsep ini menekankan pada banyaknya orang lanjut usia yang masih bisa beraktivitas dengan baik, dan bahwa pengalaman orang lanjut usia sangat berguna bagi lingkungan tempat dia berada, baik itu untuk lingkungan kerja maupun tempat tinggal (Schaie, 1977).

Pada artikelnya yang berjudul "Reviewing the definition of elderly", Orimo et al. (2006) menuliskan bahwa karena jumlah lanjut usia yang sehat semakin banyak, maka lanjut usia seharusnya didasarkan atas status kesehatan dan bukan usia. Kelebihan pendekatan ini adalah kita bisa membuat kategorisasi usia berdasarkan keberfungsian seseorang sehingga pembuat kebijakan akan mendapatkan gambaran yang sesungguhnya dari keberfungsian masyarakatnya.

Idealnya negara melakukan kategorisasi usia masyarakatnya berdasarkan status kesehatan dan berdasarkan fungsi. Angka usia sebaiknya tidak menjadi patokan dalam menyusun kebijakan negara, utamanya kebijakan yang terkait kesehatan. Akan tetapi, pendekatan ini juga memiliki kelemahan, yaitu membutuhkan upaya dan proses yang sulit dan mahal. Hal ini dikarenakan untuk bisa membuat kategorisasi harus dilakukan evaluasi orang per orang. Pada praktiknya hal ini sulit dilakukan.

Berdasarkan faktor kemudahan dalam implementasi, maka negara sebaiknya masih menggunakan pendekatan chronological age dalam mendefinisikan lanjut usia. Namun demikian, upaya mengukur functional age masyarakat tetap diperlukan agar negara bisa membuat kebijakan yang tepat.

\section{Kategorisasi Lanjut Usia}

Upaya untuk melakukan kategorisasi lansia telah dilakukan oleh pakar dari bidang ilmu yang berbeda. Berikut kategorisasi lansia dari perspektif psikologis, kesehatan, dan ekonomi.

\section{Perspektif Psikologis}

Pakar psikologi perkembangan bernama Hurlock (2001) memasukkan lansia ke dalam tahapan kesepuluh atau terakhir dari perkembangan manusia. Hurlock (2001) melihat psikologis lansia merupakan proses kontinum sejak masa konsepsi. Ia membagi usia manusia dalam 10 tahapan, yaitu: (1) Periode prenatal yaitu konsepsi kelahiran; (2) Bayi yaitu kelahiran sampai akhir minggu kedua; (3) Masa bayi yaitu akhir minggu kedua sampai akhir tahun kedua; (4) Awal masa kanak-kanak (2-6 tahun); (5) Akhir masa kanak-kanak (6-10/12 tahun); (6) Pramasa remaja (10/12-13/14 tahun; (7) Masa remaja (13/14-18 tahun); (8) Awal masa dewasa (18-24 tahun); (9) Usia pertengahan (40-60 tahun); (10) Masa tua atau lansia (60 tahun sampai meninggal). 
Sementara pakar psikologi perkembangan sosial, Erikson, menitikberatkan pada tugas perkembangan yang harus dipenuhi seseorang. Menurut Erikson tugas perkembangan pada masa tua sangat penting karena menentukan orang tersebut mengakhiri hidupnya dengan bahagia atau putus asa. Erikson (dalam Baron \& Byrne, 2004) membagi rentang kehidupan manusia menjadi delapan tahapan berdasarkan perkembangan psikologi sosial. Erikson juga membuat daftar tugas perkembangan yang menyertai pada setiap tahap kehidupan tersebut. Berikut kategorisasi usia versi Erik Erikson:

Tabel 2

Tahapan Perkembangan Psikologi Sosial Erikson

\begin{tabular}{ll}
\hline \multicolumn{1}{c}{$\begin{array}{c}\text { Tahap } \\
\text { Kehidupan }\end{array}$} & \multicolumn{1}{c}{ Tugas Perkembangan } \\
\hline Masa bayi & Tahap percaya versus tidak percaya \\
Masa kanak- & $\begin{array}{l}\text { Tahap otonomi versus rasa malu dan } \\
\text { ragu-ragu }\end{array}$ \\
Usia prasekolah & Tahap inisiatif versus rasa bersalah \\
Usia sekolah & Tahap industri versus rasa rendah diri \\
Masa remaja & $\begin{array}{l}\text { Tahap identitas versus keraguan akan } \\
\text { identitas }\end{array}$ \\
Masa awal & Tahap keakraban versus rasa terasing \\
dewasa & Tahap produktif versus keadaan pasif \\
Masa dewasa & Tahap integritas versus putus asa \\
Masa tua & Suling
\end{tabular}

Sumber: Cherry, 2018

Berdasarkan teori Erik Erikson tugas perkembangan orang lansia adalah mencapai integritas agar menjadi lansia yang bahagia. Jika hal itu tidak tercapai maka akan menciptakan lansia yang putus asa (despair) dan tidak bahagia. Pada masa lansia yang menjadi tantangan adalah bagaimana caranya agar lansia dapat menjalani hidup yang berkualitas di tengah-tengah begitu banyaknya perubahan yang terjadi. Perubahan itu baik secara fisik, psikis, sosial, maupun ekonomi.

\section{Perspektif Kesehatan}

Jika ilmu psikologi melakukan klasifikasi usia berdasarkan tahapan perkembangan mental, maka ilmu kesehatan membaginya berdasarkan kondisi fisik. Al Amin (2017) menuliskan bahwa klasifikasi usia menurut Kementerian Kesehatan sebagai berikut: 1) Masa Balita: 0-5 Tahun;
2) Masa Kanak-Kanak: 5-11 Tahun; 3) Masa Remaja Awal: 12-16 Tahun; 4) Masa Remaja Akhir: 17-25 Tahun; 5) Masa Dewasa Awal: 26-35 Tahun; 6) Masa Dewasa Akhir: 36-45 Tahun; 7) Masa Lansia Awal: 46-55 Tahun; 8) Masa Lansia Akhir: 56-65 Tahun; dan 9) Masa Manula: > 65 Tahun.

Lansia dalam perspektif kesehatan dimulai saat masa lansia awal yaitu usia 46-55 tahun. Ini adalah masa peralihan menjadi tua yang diikuti dengan penurunan fungsi organ dan jumlah hormon pada tubuh. Setelah itu, ketika memasuki masa lansia akhir (56-65) pada sebagian lansia mulai ada penurunan fungsi indra seperti indera penglihatan dan pendengaran. Kemudian ketika memasuki masa manula ( $>65$ tahun) fungsi indera pada sebagian orang menjadi semakin menurun.

\section{Perspektif Ekonomi}

Berbeda dengan perspektif psikologi dan kesehatan yang fokus pada kondisi fisik dan mental, maka perspektif ekonomi membagi usia penduduk berdasarkan produktivitasnya. Usia penduduk terbagi atas penduduk produktif, yaitu mereka yang berusia antara 15-60 tahun dan yang tidak produktif, mereka yang berusia 0-15 dan 60 ke atas. Para ekonom dan aktuaris menghitung implikasi keuangan dan kebijakan pensiun menggunakan old-age dependency ratio yang dihitung berdasarkan jumlah total populasi yang berusia di atas 60 tahun dibagi dengan jumlah populasi yang berusia 15-60 tahun.

Menurut theglobaleconomy.com (2020), persentase penduduk Indonesia yang tidak bekerja pada tahun 2018 dibandingkan dengan penduduk yang bekerja adalah 47,95\%. Artinya setiap 100 orang usia produktif menanggung beban 48 orang penduduk nonproduktif. Bandingkan dengan negara tetangga Malaysia yang sebesar 44,23\% atau Singapura 31,13\%. Semakin bertambah jumlah penduduk lansia akan menambah beban tanggungan penduduk usia produktif (BPS, 2019).

\section{Kajian Ilmiah Terkini tentang Lansia}

Minat ilmuwan terhadap kajian lansia meningkat dalam beberapa tahun terakhir. Hal ini memunculkan beberapa konsep terkait 
lansia yaitu, active ageing, healthy ageing, dan successful ageing. Konsep healthy ageing lebih menitikberatkan pada penurunan tingkat kematian, ketiadaan penyakit kronis, menurunkan tingkat morbiditas, dan status fungsional yang bagus (Costa \& Veloso, 2014). Sementara konsep successful ageing menekankan pada menurunkan kemungkinan menjadi sakit pada lansia, meningkatkan kapasitas fungsional dan keterlibatan dalam kehidupan (Rowe \& Kahn, 1997). Penggunaan kata sukses juga bermakna materialistis, status, dan pencapaian (Peel, Bartlett, \& McLure, 2004).

Konsep active ageing memfokuskan diri pada keberfungsian lansia terhadap lingkungannya. Di antara ketiga pendekatan itu WHO lebih memilih active ageing. WHO (2002) mendefinisikan active ageing sebagai penuaan aktif, yaitu proses mengoptimalkan peluang untuk kesehatan, partisipasi, dan keamanan untuk meningkatkan kualitas hidup orang tua seiring bertambahnya usia. WHO melalui salah satu departemennya yaitu Noncommunicable Disease Prevention and Health Promotion Department, telah mengingatkan semua negara untuk segera menyadari adanya sebuah tantangan di masa mendatang, yaitu terjadinya bonus lansia. Salah satu cara menanganinya yaitu dengan membuat kebijakan tentang lansia dengan pendekatan konsep active ageing. Konsep ini kemudian dijadikan oleh WHO sebagai konsep dasar dalam penyusunan kerangka kerja WHO terkait lansia yang diharapkan akan diterapkan di seluruh dunia.

Konsep active ageing mendorong terciptanya lansia yang aktif dengan meningkatkan kualitas hidup melalui tiga pilar utama active ageing yaitu kesehatan, keamanan, dan partisipasinya dalam masyarakat. Pilar kesehatan, maksudnya memfokuskan pada menurunkan faktor risiko dan meningkatkan faktor perlindungan. Pilar keamanan, yaitu ketika program dan kebijakan mendukung kebutuhan keamanan fisik, sosial, dan finansial. Selain itu, juga melindungi hakhak lansia. Terakhir pilar partisipasi, yaitu ketika kebijakan dan program mendukung partisipasi penuh lansia secara sosio-ekonomi, budaya, dan aktivitas spiritual lansia. Ketiga pilar tersebut tercermin dari lanjut usia yang masih mampu bekerja, masih berpartisipasi dalam kegiatan sosial, ekonomi, budaya, keagamaan, dan bahkan kegiatan-kegiatan sipil kewarganegaraan (civic).

Active ageing terdiri dari dua determinan umum yaitu budaya dan gender, serta enam determinan khusus yaitu ekonomi, pelayanan kesehatan dan sosial, perilaku, pribadi, lingkungan fisik, dan sosial. Keenam determinan active ageing tersebut ditujukan untuk meningkatkan kualitas hidup dan memperpanjang usia harapan hidup yang sehat (healthy life expectancy) (WHO 2001), seperti ditunjukkan pada Bagan 1.

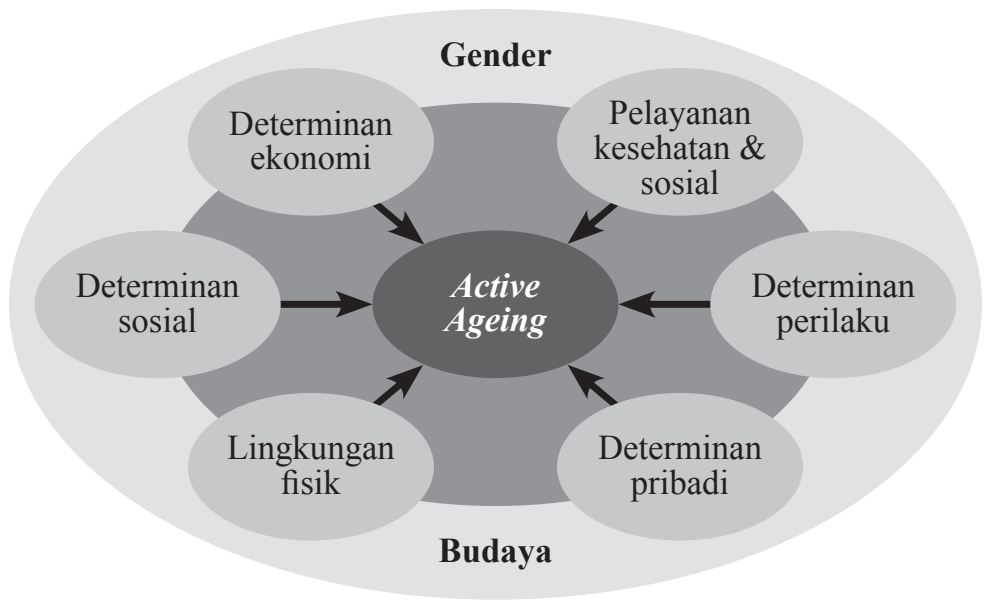

Bagan 1. Determinan Active Ageing

Sumber: WHO, 2002 
Determinan pertama yaitu kesehatan dan pelayanan sosial terfokus pada melakukan promosi kesehatan, tindakan preventif atas penyakit dan pelayanan kuratif berupa pelayanan kesehatan yang prima, pengasuhan jangka panjang, dan pelayanan kesehatan mental dan fisik. Determinan kedua yaitu perilaku mendorong masyarakat untuk mengadopsi gaya hidup yang sehat dengan aktivitas fisik, makanan sehat, tidak merokok, tidak meminum minuman keras dan penggunaan obat-obatan secara bijak. Determinan ketiga yaitu faktor personal. Kesehatan lansia dipengaruhi faktorfaktor seperti genetis, lingkungan, gaya hidup, nutrisi, dan kesempatan hidup (Kirkwood, 1996). Faktor lain yang berpengaruh adalah kecerdasan, kapasitas kognitif, kemampuan menyelesaikan masalah, dan kemampuan beradaptasi terhadap perubahan. Determinan keempat adalah terkait lingkungan fisik. Lingkungan yang ramah lansia seperti arsitektur rumah yang sesuai, tetangga yang mendukung, merupakan hal-hal yang sangat berpengaruh dengan kondisi kesehatan lansia. Determinan kelima adalah lingkungan sosial yaitu berupa dukungan sosial, kesempatan belajar sepanjang hayat, perdamaian dan perlindungan dari kekerasan. Determinan keenam adalah ekonomi. Terdapat tiga aspek dari ekonomi yang berpengaruh terhadap active ageing, yaitu penghasilan, pekerjaan, dan pelindungan sosial (WHO, 2002).

\section{Kategori Usia Lansia}

Salah satu alasan Kementerian Sosial mendorong revisi UU Lansia adalah untuk mengubah batasan kategori usia lansia yang sebelumnya adalah 60 tahun menjadi 65 tahun. Hal ini memunculkan pertanyaan, berapakah batasan usia lansia yang ideal di Indonesia? Terdapat beberapa pendapat terkait batasan awal usia yang masuk dalam kategori lanjut usia. Sebagian menggunakan usia 60 sebagai batasan awal, sementara sebagian lainnya usia 65. Perserikatan Bangsa-Bangsa (PBB) menggunakan usia 60 tahun sebagai batasan awal lansia. Batasan usia 60 tahun ini umumnya digunakan di negara berkembang, sementara di negara-negara maju batasan umur yang digunakan adalah 65 tahun dan lebih (WHO, 2013). Kategori usia lanjut 65 tahun dan lebih ini juga digunakan oleh organisasi dunia International Labour Organization (ILO) untuk menghitung angka ketergantungan penduduk. Perbedaan kategori umur tersebut umumnya disesuaikan dengan kondisi lanjut usia di negara maju dan negara berkembang seiring dengan capaian UHH.

Menurut peneliti batasan usia yang tepat di Indonesia saat ini adalah masih 60 tahun. Pertimbangannya adalah meskipun UHH masyarakat Indonesia telah semakin meningkat, akan tetapi secara umum belum diiringi dengan lansia yang berkualitas, baik dari sisi ekonomi, kesehatan, maupun pendidikan. Peningkatan batasan usia menjadi 65 akan mengakibatkan berbagai program bantuan untuk lansia menyasar pada masyarakat yang berusia 65 tahun ke atas. Masyarakat yang berusia 60-64 yang sebelumnya mendapatkan bantuan menjadi tidak lagi berhak. Upaya mempertahankan ambang batas di usia 60 tahun adalah dalam rangka melindungi lansia. Pandangan ini sejalan dengan pendapat dua orang pakar yang menjadi narasumber penelitian ini, yaitu pakar studi lanjut usia dari Universitas Indonesia Ibu Dr. Lilis Heri Mis Cicih dan Made Diah Lestari S.Psi., M.Psi.

\section{Mendesakkah Revisi Undang-Undang tentang Lanjut Usia?}

Saat ini dengan persentase lansia sebesar $9,6 \%$ dari ambang batas 10\%, maka Indonesia telah berada di pintu gerbang negara dengan kategori struktur penduduk tua (ageing population). Hal ini diperkuat dengan fakta pada tahun 2019 telah ada lima provinsi di Indonesia yang lansianya telah mencapai di atas 10\%, yaitu DI Yogyakarta $(14,50 \%)$, Jawa Tengah (13,36\%), Jawa Timur $(12,96 \%)$, Bali $(11,30 \%)$, dan Sulawesi Barat $(11,15 \%)$ (BPS, 2019). Menurut data BPS (2020) kondisi Indonesia di tahun 2020 untuk setiap 100 orang usia produktif menanggung beban 48 orang penduduk nonproduktif. Data BPS di tahun 2019 persentase lansia Indonesia sebesar $9,6 \%$ atau sekitar 25,64 juta orang. Berdasarkan data tersebut, secara ekonomi negara harus mengupayakan langkah-langkah agar populasi yang masuk dalam kategori usia tidak produktif (lansia dan anak-anak) dapat ditanggung bebannya oleh tenaga kerja yang produktif. 
Dari sudut pandang kesehatan, hasil Survei Sosial Ekonomi Nasional (Susenas) yang dilakukan bulan Maret 2019 menunjukkan bahwa status kesehatan penduduk lansia Indonesia juga mengkhawatirkan. Separuh lansia Indonesia mengalami keluhan kesehatan (BPS, 2019). Angka kesakitan (morbidity rate) penduduk lansia pada tahun 2019 adalah 26,20\%, yang artinya dari 100 orang lansia 26 orang di antaranya mengalami sakit. Pola hidup sehat pada lansia juga perlu mendapatkan perhatian, karena $24,30 \%$ penduduk lansia mempunyai kebiasaan merokok.

Dari sudut pandang psikologis, saat ini tidak tersedia data menyeluruh terkait kondisi psikologis lansia Indonesia. Akan tetapi, kita dapat melihat indikasinya dengan melihat mereka tinggal dengan siapa, latar belakang pendidikannya, dan dari sejumlah hasil-hasil penelitian dengan sampel lansia Indonesia.

Data Susenas yang dilakukan di bulan Maret 2019 menunjukkan bahwa sebanyak 9,38\% lansia tinggal sendirian. Proporsi jenis kelamin dari lansia tersebut $13,39 \%$ adalah lansia perempuan dan 4,98\% lansia laki-laki. Lansia yang pasangannya telah meninggal dunia dan yang tinggal berjauhan dengan anak-anaknya cenderung merasa kesepian. Jumlah lansia yang tinggal sendirian lebih banyak di pedesaan $(10,10 \%)$ dibanding di perkotaan $(8,74 \%)$ (Hakim, 2020). Berikut gambaran status tinggal lansia di Indonesia (Grafik 3).

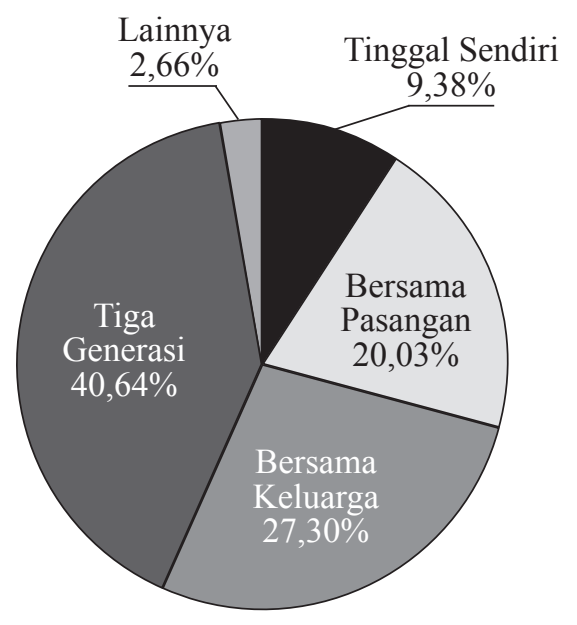

\footnotetext{
Grafik 3. Persentase Status Tinggal Lansia, Tahun 2019

Sumber: Diolah dari data BPS, Susenas Maret 2019
}

Tinggal sendirian akan memunculkan rasa kesepian yang akan berdampak pada kemunduran secara fisik maupun psikis. Penelitian menunjukkan adanya hubungan antara kesepian dan isolasi sosial dengan tekanan darah tinggi, penyakit jantung, obesitas, sistem imun yang rendah, depresi, penurunan kognitif, alzheimer, bahkan kematian (National Institute on Ageing, 2019). Penelitian Puspadewi dan Rekawati (2017) pada lansia di Jakarta menunjukkan dari 101 lansia sebanyak 57,4\% mengalami depresi. Hasil yang hampir sama didapat oleh Mahadewi dan Ardani (2018) yang meneliti 40 lansia di Bali, dengan temuan $50 \%$ di antaranya mengalami depresi dan hidup dengan kualitas yang buruk. Penelitian terhadap kualitas hidup lansia di Padang oleh Utami, Gusyaliza, dan Ashal (2018) menemukan dari 100 orang respondennya sebanyak 50\% mengalami depresi. Sementara penelitian di Surakarta oleh Azzahro dan Rosyid (2016) menunjukkan dari 28 responden sebanyak $66 \%$ mengalami depresi ringan, 29\% depresi sedang, dan $0 \%$ depresi berat.

Problem lansia di Indonesia lainnya adalah pendidikannya yang rendah. Sebanyak 33,26\% lansia Indonesia tidak menyelesaikan tingkat sekolah dasar. Sebanyak 30,88\% menyelesaikan tingkat sekolah dasar atau sederajat, dan sebanyak $15,53 \%$ bahkan tidak pernah mengenyam bangku sekolah (BPS, 2012). Berikut gambaran persentase latar belakang pendidikan lansia di Indonesia (Grafik 4).

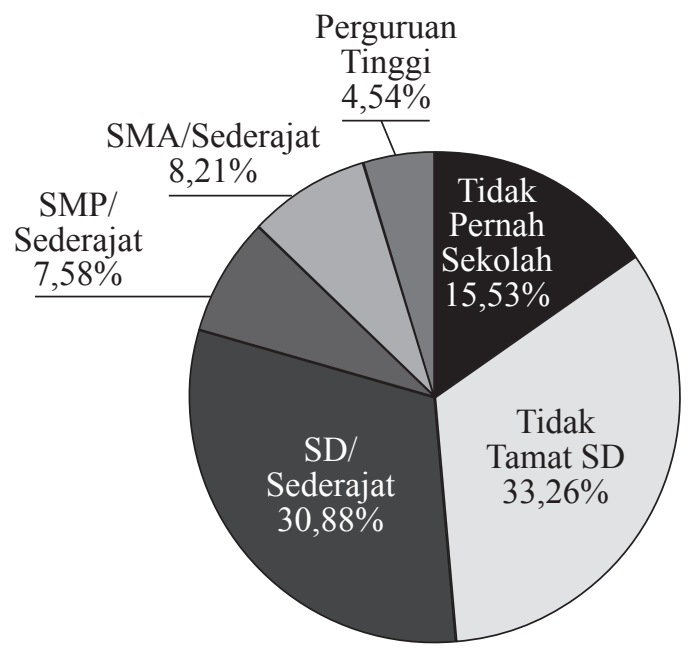

Grafik 4. Persentase Pendidikan Lansia, Tahun 2019

Sumber: Diolah dari data BPS, Susenas Maret 2019 
Grafik 4 di atas menunjukkan secara jelas potret sumber daya manusia lansia Indonesia yang masih tertinggal. Sementara menurut BPS (2012) terdapat hubungan antara tingkat pendidikan dengan status ekonomi.

Diprediksi angka populasi lansia akan mencapai sekitar 35 juta pada tahun 2025 (PBB dalam WHO, 2002). Rasio penduduk nonproduktif akan semakin lebih besar dari penduduk produktif, dengan kualitas kesehatan mayoritas lansia yang buruk, pola hidup lansia yang tidak sehat, persentase lansia tinggal sendiri yang lebih besar, serta tingkat pendidikan lansia yang rendah, dapat mengakibatkan depresi bagi para lansia. Oleh karena itu, negara harus segera melakukan langkah-langkah nyata untuk mengantisipasi bonus lansia.

Indonesia saat ini telah mempunyai Undang-Undang Nomor 13 Tahun 1998 tentang Kesejahteraan Lanjut Usia (UU Lansia). Namun demikian, UU tersebut belum bisa menjawab tantangan yang dihadapi kompleksitas permasalahan lansia di masa mendatang. Beberapa kelemahan mendasar adalah belum melihat lansia dengan prinsip kelanjutusiaan, belum menggunakan konsep active ageing, belum maksimal mengakomodir hak-hak lansia, masih lemahnya proteksi lansia, lemahnya pendataan, serta kinerja kementerian/lembaga pusat dan daerah yang belum terintegrasi dengan baik. Beberapa kelemahan UU tersebut menjadi poin-poin usulan perbaikan yang akan dibahas pada sub judul "Peran DPR RI Menangani Bonus Lansia" di bawah ini. Berdasarkan uraian di atas maka revisi UU Lansia mendesak dilakukan.

\section{Peran DPR RI dalam Menangani Bonus Lansia}

DPR dapat memainkan peran yang sangat penting dalam upaya menciptakan lansia yang sejahtera dengan menjadikan revisi UU Lansia sebagai prioritas untuk segera disusun dan dibahas. Dalam pembahasannya, DPR perlu menekankan beberapa prinsip tambahan yang penting dalam revisi UU tersebut untuk mendorong terciptanya lansia yang sejahtera. Beberapa prinsip tersebut adalah sebagai berikut:

Pertama, RUU revisi harus mengakomodir prinsip kelanjutusiaan. Prinsip kelanjutusiaan merupakan salah satu prinsip penting guna mewujudkan lansia sejahtera (Cicih, 2020). Secara umum yang dimaksud kelanjutusiaan adalah pendekatan memahami lanjut usia sebagai sebuah siklus hidup (life cycle approach). Penanganan lansia tidak bisa dilakukan secara terpisah-pisah. Penanganan lansia tidak bisa dilakukan hanya ketika orang telah menjadi lansia, karena bagaimana kondisi lansia saat ini sangat tergantung kehidupan yang dijalani lansia sejak awal kehidupan. Lansia merupakan proses panjang sejak lansia tersebut kecil, bahkan sejak belum dilahirkan. Prinsip kelanjutusiaan dapat dijadikan pedoman agar kebijakan yang disusun oleh negara bertujuan terciptanya warga negara yang sehat dan berkualitas yang pengelolaannya telah dimulai sejak masa di dalam kandungan, masa balita, masa kanak kanak, masa remaja awal, masa remaja akhir, masa dewasa awal, masa dewasa akhir, masa lansia awal, masa lansia akhir, dan masa manula (Hakim, 2020).

Kajian tentang lansia mengenal teori penuaan primer, sekunder, dan tersier. Manusia hanya memiliki ruang untuk melakukan intervensi pada proses penuaan jenis sekunder. Penuaan sekunder bersifat patologis dan dipengaruhi gaya hidup dan lingkungan. Namun demikian, intervensi terhadap penuaan sekunder tidak bisa dihasilkan dengan intervensi kebijakan yang dimulai dari waktu ketika seseorang telah menjadi lansia. Intervensi harus dilakukan jauh sejak sebelum penuaan terjadi, bahkan sejak anak masih di dalam kandungan ibunya. Masa kehamilan yang sehat, kemudian setelah lahir hidup dengan lingkungan yang sehat jasmani rohani dan bahagia akan menghasilkan masa tua yang sehat. Intervensi dapat dilakukan melalui edukasi kepada pasangan suami istri yang baru menikah mengenai pola hubungan suami istri yang baik dan sehat, pola asuh anak (parenting) yang baik, edukasi tentang kelansiaan di bangku sekolah, serta edukasi persiapan menghadapi masa tua dan masa pensiun melalui posyandu lansia dan institusi maupun perusahaan.

Kedua, memberikan hak-hak lansia. Lansia mempunyai hak yang sama sebagai warga negara dalam kehidupan bermasyarakat, berbangsa, dan bernegara. Negara harus memfasilitasi lansia untuk mendapatkan kemudahan dan prioritas, 
terutama dalam bentuk sarana prasarana. Ketiga, pendataan lansia. Negara harus memiliki data yang akurat, lengkap, terpilah, dan mutakhir mengenai lansia. Data tersebut akan memudahkan perencanaan, pelaksanaan, dan evaluasi programprogram kerja pemerintah.

Keempat, proteksi ekonomi keluarga. Negara harus memberikan proteksi terhadap keluarga yang mempunyai lansia, supaya ekonomi keluarga tersebut terjamin (Lestari, 2020). Hal ini juga untuk mengubah mindset bagi sebagian orang yang menganggap merawat lansia adalah beban akan berubah menjadi berkah. Sebagai contoh implementasi dengan pemberian insentif bagi keluarga yang mempunyai lansia di rumahnya.

Kelima, faktor koordinasi. Sering kali kebijakan pusat dan daerah terkait lansia tidak terkoordinasi dengan baik (Lestari, 2020). Untuk itu pemerintah harus cepat merespons ketika revisi UU Lansia telah disahkan. Respons tersebut berupa segera membuat peraturan turunannya, menyusun perencanaan yang baik, kemudian mensosialisasikannya ke semua kementerian dan lembaga, serta pemerintah daerah baik itu provinsi maupun kabupaten/kota. DPR melalui pelaksanaan fungsi pengawasan, dapat mendesak pemerintah untuk melakukan apa yang seharusnya mereka lakukan.

\section{Penutup}

Meningkatnya Usia Harapan Hidup (UHH) di Indonesia dan terus bertambahnya penduduk berusia lanjut, menjadikan Indonesia sebagai salah satu negara dengan persentase lansia tertinggi di dunia. Oleh karena itu, revisi Undang-Undang Nomor 13 Tahun 1998 tentang Kesejahteraan Lanjut Usia (UU Lansia) mendesak untuk dilakukan. Kita dapat mengacu kajian lansia dari World Health Organization (WHO) sebagai dasar kebijakan untuk mewujudkan lansia yang lebih berkualitas.

Adapun batasan kategori usia lansia dapat menggunakan batasan yang sebelumnya, yaitu 60 tahun. DPR RI memainkan peran strategis dengan mendorong revisi UU Lansia menjadi RUU prioritas untuk segera disusun dan dibahas. Beberapa poin yang perlu dimasukkan dalam revisi UU Lansia adalah tentang prinsip kelanjutusiaan, hak-hak lansia, pendataan lansia, dan proteksi ekonomi bagi lansia.

\section{Ucapan Terima Kasih}

Penulis ingin mengucapkan terima kasih kepada Tim Perancang Undang-Undang Badan Keahlian DPR RI yang telah terlibat dalam pengambilan data, yaitu Ketua Tim Bagus Prasetyo, S.H., M.H., Nita Ariyulinda, S.H., M.H., Yuwinda Sari Pujianti, S.H., Nova Manda Sari, S.H., M.H., Nur Ghenasyarifa Albany Tanjung, S.H., Suratman, S.H., M.H., dan last but not least Dr. Lilis Heri Mis Cicih dan Made Diah Lestari, S.Psi., M.Psi, dua orang narasumber yang telah memberikan banyak masukan.

\section{Daftar Pustaka}

Al Amin, M. (2017). Klasifikasi Kelompok Umur Manusia Berdasarkan Analisis Dimensi Fraktal Box Counting Dari Citra Wajah Dengan Deteksi Tepi Canny. MATHunesa (Jurnal Ilmiah Matematika), 2(6).

Astuti, I. (2018, May 24). Kemensos Dorong Revisi UU Lansia. Media Indonesia. Retrieved from https://mediaindonesia.com/read/detail/162798kemensos-dorong-revisi-uu-lansia, on May 30, 2020 .

Azzahro, F. D. \& Rosyid, F. N. (2016). Hubungan antara tingkat depresi dengan kualitas hidup lanjut usia di Panti Wredha Dharma Bhakti Pajang Surakarta. Universitas Muhammadiyah Surakarta (Naskah Publikasi).

Badan Pusat Statistik. (2019). Statistik Penduduk Lanjut Usia 2014. Jakarta: Badan Pusat Statistik.

Badan Pusat Statistik. (2014, February 18). Dependency Ratio menurut Provinsi, 2010 2035. Retrieved from https://www.bps.go.id/ statictable/2014/02/18/1275/dependency-ratiomenurut-provinsi-2010-2035.html, on June 25, 2020.

Baron, R. A. \& Byrne, D. (2004). Social Psychology (10th Edition). New Delhi: Pearson Education.

Bloom, D., Canning, D., \& Malaney, P. N. (1999). Demographic change and economic growth in Asia. CID Working Paper Series. 
Cherry, K. (2018, June 5). Erik Erikson's stages of psychosocial development. Retrieved from https://www.verywellmind.com/erik-eriksonsstages-of-psychosocial-development-2795740, on April 5, 2020.

Cicih, L. H. M. (2020). Pengumpulan Data RUU Lansia/Pewawancara: Tim RUU Lansia BKD, Badan Keahlian DPR RI.

Costa, L. \& Veloso, A. (2015, June). The gamer's soul never dies: Review of digital games for an active ageing. In The 2015 10th Iberian Conference on Information Systems and Technologies (CISTI) (pp. 1-6). IEEE.

Forman, D. E., Berman, A. D., McCabe, C. H., Baim, D. S., \& Wei, J. Y. (1992). PTCA in the elderly: The "young-old" versus the "old-old". Journal of the American Geriatrics Society, 40(1), 19-22. doi:10.1111/j.1532-5415.1992. tb01823.x. PMID 1727842.

Fry, C. L. (1976). The ages of adulthood: a question of numbers. Journal of Gerontology, 31(2), 170 177.

Hakim, L. N. (2020). Perlindungan Lanjut Usia Pada Masa Pandemik Covid-19. Info Singkat, XII (10/ II/Puslit/Mei/2020).

Hurlock, E. B. (2001). Developmental psychology. New Delhi: Tata McGraw-Hill Education.

Kirkwood, T. (1996). Mechanisms of Ageing. In Ebrahim S and Kalache A (eds), Epidemiology in Old Age. London: BMJ Publishing Group

Lestari, M. D. (2020). Pengumpulan Data RUU Lansia/Pewawancara: Tim RUU Lansia BKD, Badan Keahlian DPR RI.

Mahadewi, I. G. A. (2018). Hubungan Tingkat Depresi Dengan Kualitas Hidup Pada Lansia Di Panti Sosial Werdha Wana Seraya Denpasar Bali. E-Jurnal Medika Udayana, 7(8), 1-8. Retrieved from https://ojs.unud.ac.id/index.php/ eum/article/view/41632

National Institute on Aging. Social isolation, loneliness in older people pose health risks. Retrieved from https://www.nia.nih.gov/news/ social-isolation-loneliness-older-people-posehealth-risks, on April 28, 2020

Orimo, H., Ito, H., Suzuki, T., Araki, A., Hosoi, T., \& Sawabe, M. (2006). Reviewing the definition of "elderly". Geriatrics \& gerontology international, 6(3), 149-158.
Peel, N., Bartlett, H., \& McClure, R. (2004), Healthy ageing: how is it defined and measured? Australasian Journal on Ageing, 23: 115-119. doi:10.1111/j.1741-6612.2004.00035.x.

Purnamawati, D. (2019, July 10). 60 Tahun Termasuk Produktif Mensos Minta Usia Lansia Direvisi. Antara Bengkulu. Retrieved from https:// bengkulu.antaranews.com/berita/72346/60tahun-termasuk-produktif-mensos-minta-usialansia-direvisi, on February 26, 2020.

Puspadewi, A. A. R. \& Rekawati, E. (2017). Depresi berhubungan dengan kualitas hidup lansia di Panti Sosial Tresna Werdha di Jakarta. Jurnal Keperawatan Indonesia, 20(3), 133-138.

Ram, N., Gerstorf, D., Fauth, E., Zarit, S., \& Malmberg, B. (2010). Ageing, disablement, and dying: Using time-as-process and timeas-resources metrics to chart late-life change. Research in Human Development, 7(1), 27-44.

Rapih, S. (2019, September 14). Meraih Bonus Demografi Kedua. Solopos.com. Retrieved from https://www.solopos.com/meraih-bonusdemografi-kedua-1017790, on May 30, 2020.

Rowe, J. W., \& Kahn, R. L. (1997). Successful Ageing. The gerontologist, 37(4), 433-440.

Schaie, K. W. (1977). Functional Age and Retirement. Paper in Symposium on social and biological aspects of retirement age, International Society for the study of behavioral development. Pavia, Italy, September 21, 1977.

TheGlobalEconomy.com. Indonesia: Age dependency ratio. Retrieved from https:// www.theglobaleconomy.com/Indonesia/Age dependency_ratio/, on April 28, 2020.

Utami, A. W., Gusyaliza, R., \& Ashal, T. (2018). Hubungan kemungkinan depresi dengan kualitas hidup pada lanjut usia di Kelurahan Surau Gadang Wilayah Kerja Puskesmas Nanggalo Padang. Jurnal Kesehatan Andalas, 7(3), 417-423.

United Nations Population Fund (UNFPA). (2012). Ageing in the Twenty-First Century: A Celebration and A Challenge. Retrieved from https://www.unfpa.org/sites/default/files/pubpdf/UNFPA-Exec-Summary.pdf, on February 26, 2020.

World Health Organization (WHO). (2002). Active Ageing: A policy framework (No. WHO/NMH/ NPH/02.8). Geneva: World Health Organization. 
Zizza, C. A., Ellison, K. J., \& Wernette, C. M. (2009). "Total water intakes of community-living middle-old and oldest-old adults". The Journals of Gerontology Series A: Biological Sciences and Medical Sciences, 64A(4): 481-486. doi:10.1093/ gerona/gln045. PMC 2657166. PMID 19213852. 